\title{
Postgraduate Students' Perceptions of Support Services Rendered by a Distance Learning Institution
}

\author{
Mapheleba Lekhetho ${ }^{1}$ \\ ${ }^{1}$ Department of Educational Leadership and Management, College of Education, University of South Africa, Pretoria, \\ South Africa \\ Correspondence: Mapheleba Lekhetho, Department of Educational Leadership and Management, College of \\ Education, University of South Africa, Pretoria, South Africa.
}

Received: November 22, 2021

Accepted: December 21, 2021

Online Published: December 23, 2021

doi:10.5430/ijhe.v11n 7 p24

URL: https://doi.org/10.5430/ijhe.v11n7p24

\begin{abstract}
Postgraduate studies are generally draining for most students because of the high rigour and cognitive demands required. They are even more arduous for students in a distance-learning context as most of them are full-time employees and lack enough time for their studies. Consequently, they tend to have low success rates due to a lack of required academic and research skills, low English proficiency, and inadequate student support. Underpinned by Simpson's student support model, this research adopted a qualitative approach and a focus group technique to probe nine Ethiopian doctoral students about their perceptions of the support provided by the University of South Africa (Unisa). From a thematic analysis of the themes that recurred, the findings revealed that despite the challenges, most students appreciated the support provided, particularly by supervisors who guided them efficiently and gave them feedback promptly. To improve graduation rates, it is recommended that supervisors be trained in effective supervision and support of students from diverse linguistic and educational backgrounds.
\end{abstract}

Keywords: distance education, postgraduate education, student support, persistence

\section{Introduction}

Although distance education mode has gained currency as a viable alternative that increases access to higher education, it faces challenges of higher attrition and lower graduation rates than face-to-face learning in conventional universities (Simpson, 2016), particularly at the postgraduate level, as most students are mature, full-time employees. Many students start but never complete their doctoral studies, which dampens their self-esteem and career prospects (Torka, 2020; van Rooij, Fokkens-Bruinsma \& Jansen, 2019). This could be attributed to the increasing number of underprepared postgraduate students, leading to increased lecturers' workload, inadequate supervision, and insufficient student support. The English language barrier is another hurdle that slows down progress and increases the dropout of many postgraduate students who are second-language speakers from diverse cultural, linguistic, and educational backgrounds (Manyike, 2017; Martirosyan, Bustamante \& Saxon, 2019). This diversity makes the supervisory role more complex due to the increasing pressure on higher education institutions (HEIs) and supervisors to provide high-quality supervision to attract and retain more students (Baydarova, Collins \& Ait Saadi, 2021). This study focused on the Ethiopian doctoral students registered in the College of Education and probed their perceptions of the support provided by Unisa.

As part of the Ethiopian government's human development capacity programme, Unisa has been offering postgraduate education to Ethiopian students, mostly doctoral degrees to lecturers teaching at different public universities and senior public servants since 2007. However, this bilateral programme has been fraught with a systemic challenge of low graduation rates. As Table 1 reflects, as of 2020, the College of Education had only produced 87 Ethiopian doctoral graduates since 2007, which is far less than the number of registered students over the same period. For instance, in 2018, 92 students were registered, 92 in 2019 and 104 in 2020, while only 18, 9, and 8 graduated in the same years (UNISA-Ethiopia Centre, 2021). These figures indicate that students stay longer in the system, which constitutes a high wastage rate. Poor completion rates may damage the academic reputations of institutions and their capacity to attract promising students and funding (Simpson, 2013; Torka, 2020). 
Table 1. Ethiopian PhD enrolments and graduates by year in the College of Education

\begin{tabular}{|c|c|c|c|c|c|c|c|c|c|c|}
\hline \multicolumn{11}{|c|}{ Student enrolment by year } \\
\hline Stage & 2011 & 2012 & 2013 & 2014 & 2015 & 2016 & 2017 & 2018 & 2019 & 2020 \\
\hline Thesis/dissertation & 39 & 48 & 52 & 91 & 98 & 88 & 82 & 75 & 70 & 67 \\
\hline Proposal & 50 & 55 & 68 & 25 & 19 & 13 & 15 & 17 & 22 & 37 \\
\hline Total & 89 & 103 & 120 & 116 & 117 & 101 & 97 & 92 & 92 & 104 \\
\hline \multicolumn{11}{|c|}{ Number of graduates per year } \\
\hline Total & $1(1.1 \%)$ & $\mathbf{0}$ & $6(5 \%)$ & $6(5.2 \%)$ & $9(7.7 \%)$ & $12(11.9 \%)$ & $18(18.6 \%)$ & $18(19.6 \%)$ & $9(9.8 \%)$ & $8(7.7 \%)$ \\
\hline
\end{tabular}

Source: UNISA-Ethiopia Centre (2021)

This study probed the Ethiopian postgraduate students' perceptions of Unisa's student support services (SSS) to gauge their satisfaction levels. SSS refers to the strategies designed to empower students to fulfil their learning, career, and personal potential and enhance their retention, persistence, and success (Tinto, 2017). It is intended to aid students to master the required material and succeed in their studies, particularly those at a high risk of failure (Carr \& London, 2019). SSS is also meant to ease students' adjustment to the HEI and enhance their learning experience and success since many enter universities underprepared, particularly for the rigorous doctoral studies. Therefore, HEIs should provide appropriate support that reduces students' anxieties and attrition rates, fosters a sense of community, enhances education quality and learning experience, and bolsters persistence, motivation, and success (Simpson, 2016).

The above scenario relates to Tinto's student integration theory, which postulates that SSS should facilitate students' integration into the intellectual and social life of the institution through successful learning (academic integration) and interactions with peers (social integration), which enhances their commitment and persistence (Tinto, 2017). While HEIs seek to improve student retention, students do not want to be retained but to persist. Therefore, institutions should support them to do so (Tinto, 2017) by providing "support which could change access into success" (Mays, 2000, p. 1).

To succeed in the higher education market, universities should provide quality services to students (customers) to avoid losing them to their competitors and adopt a customer-led approach to increase their satisfaction. Student satisfaction enables HEIs to attract new students, retain current ones, and improve their performance, progression, and graduation rates (Jancey \& Burns, 2013). SSS is meant to (a) improve retention and graduation rates of students; (b) enhance achievement rates; and (c) foster an institutional climate that supports the success of low-income and first-generation university students and those with disabilities (Chaney, Muraskin, Cahalan \& Goodwin, 1998). SSS providers should, therefore, identify students at a high risk of failure and dropout and provide timely support to enhance their intrinsic motivation, persistence, and success. High success rates are pivotal for the academic and financial viability of South African HEIs since the government uses student throughput rates to determine their subsidies.

\subsection{Institutional Context}

The evolvement of Unisa can be categorised into three distinct phases: first founded in 1873 as an examining body, a correspondence institution in 1946, and lastly, a dedicated distance education university with the merger of two other distance education providers in 2004 (Prinsloo, 2019). It is the oldest distance education institution in Africa and one of the mega-universities in the world, with an official enrolment of 389,876 students as of 2021 (Gasa \& Gumbo, 2021; Unisa, 2021). Of this total, 97,435 (25\%) were enrolled in the College of Education, which creates organisational inefficiency due to the insufficient coordination of activities across divisions and student support.

In the UK, ODL institutions generally have low graduation rates compared to full-time institutions (Simpson, 2016). For instance, in 2015 , the average graduation rate for full-time HEIs was $82 \%$, but only $16 \%$ for the UK Open University and 6\% for Unisa (Simpson, 2016). This discrepancy is attributed to the "distance education deficit", which highlights a substantial difference between the graduation rates of conventional universities and ODL institutions (Sánchez-Elvira Paniagua \& Simpson, 2018, p. 4). It is caused by students' isolation from campus, lecturers, and other students who create a rich academic ambience, stress related to courses, and a lack of motivation to study (Budiman, 2018). This ultimately leads to a high dropout rate that Woodley and Simpson $(2014$, p. 1) call "the elephant in the room of distance education". It is attributed to lower entry qualifications since most students enter university underprepared, and ODL students' family and work commitments, as they are generally older than conventional students (Sánchez-Elvira Paniagua \& Simpson, 2018). Therefore, ODL institutions should work vigorously to stem the 
high attrition rates using some form of 'back-up' or student support mechanisms besides tuition to improve student success rates.

The low success rates of the black majority students at Unisa are ascribed to their disadvantaged backgrounds and content knowledge deficit because of the poor quality of basic education they received, which does not prepare them for higher education (Lekhetho, 2021; Manyike, 2017; Ngema \& Lekhetho, 2019). This articulation gap or disparities between the higher education curriculum and knowledge of students entering universities leads to underperformance and dropout. It is compounded by the Western orientation of the university curriculum and culture that is incompatible with the cultures of most black students from underperforming schools (Steyn, Harris \& Hartell, 2014).

\subsection{Overview of Postgraduate Education}

Postgraduate education typically consists of masters and doctoral studies, which enable HEIs to improve their research capabilities, academic reputations, and financial gain (Torka, 2020). It empowers people to create knowledge and address societal problems through impactful research. This article focuses on doctoral education, as all the participants were $\mathrm{PhD}$ students. A PhD at Unisa is research-based and designed to take roughly three years. However, in most cases, students take longer since they study part-time and lack the academic writing skills required at this level, as most of them are blacks who have been excluded from elite, private school systems that cater for Western preparations (Manyike, 2017; Martirosyan et al., 2019). Such deficits might be exacerbated by the supervisors' insufficient knowledge and guidance skills (van Rooij et al., 2019). While the average time taken to complete a PhD in South Africa is 4.8 years (Heeralal, 2015), Unisa (2021) stipulates that students must complete a doctoral programme within six years.

Comparatively, the College of Education has many postgraduate students, leading to high student-supervisor ratios that are disproportionately above the official quotas for different academic ranks: lecturer - four students; senior lecturer six; associate professor - eight; and full professor - ten. Out of 9,597 postgraduate students registered across Unisa's nine colleges in 2021, some 1,502 (15.7\%) were in the College of Education shared among 170 supervisors of different specialisations and ranks (Unisa, 2021). In some departments, supervisors supervise double their quotas, and supervision is predominantly individualised, which could disadvantage students if they are assigned inexperienced or inefficient supervisors. These large numbers of, mostly underprepared students put supervisors under immense pressure and compromise the quality of academic guidance. This could be linked to South Africa's goal to increase doctoral graduates to 5,000 per year by 2030 to meet the demand for specialised skills and innovative research needed to improve its productive capacity and global competitiveness (Manyike, 2017).

\subsection{Research Problem}

The Ethiopian postgraduate students studying through Unisa generally take longer than the stipulated time to complete their studies (UNISA-Ethiopia Centre, 2021). Some drop out due to failure to make progress, insufficient preparation, personal circumstances, and push-out factors, notably inadequate support from the institution and supervisors (Sánchez-Elvira Paniagua \& Simpson, 2018). High attrition and slow progress represent a wastage to an institution, individual students, and sponsors, as more years of investment than the official time are needed to complete degrees. This is worrying because the Ethiopian government invests heavily to develop the human resource capacity of its public universities by sponsoring lecturers for doctoral studies.

A study by Fetene and Tamrat (2021) at Addis Ababa University found that the Ethiopian PhD students took roughly $61 / 2$ years to complete their studies as many required more years of study. They established that many students were "...not fit for Ph.D. programs [and] struggle a lot in the dissertation writing", and were underprepared "for the kind of rigor that developing the thesis proposal and writing the dissertation requires" (Fetene \& Tamrat, 2021, p. 327). They also identified the students' financial challenges and family responsibilities, insufficient institutional support for $\mathrm{PhD}$ programmes, and problematic supervisor-student relationships as some of the causes of delays in $\mathrm{PhD}$ completion. Regarding Unisa, research has identified students' insufficient preparation for postgraduate studies, inadequate institutional support, and the supervisors' delays in giving students feedback as some of the factors that delay students to complete their studies within the stipulated time (Manyike, 2017).

The causes of students' low success rates are multiple and varied. From the lecturers' perspective, students make slow progress or drop out because they lack the critical research skills and the English language competency required for successful learning. However, from the managers' perspective, the problem is exacerbated by a lack of supervisory capabilities since some students often complain that certain supervisors do not respond to their queries and give them timely feedback (Nsama \& Makoe 2017). Some students claim that the university and their supervisors fail to 
support them adequately in their studies. To engage these tensions, this study sought to answer the following research question: What are the Ethiopian doctoral students' perceptions of the support services provided by Unisa?

\subsection{Conceptual Framework and Literature Review}

This study is underpinned by Simpson's (2016) distance student support model, which organises the attributes that students require to succeed in distance learning into three categories: cognitive (academic), emotional and organisational support. Cognitive support involves teaching and helping students develop the skills required for effective learning, assessment, and dealing with feedback. In postgraduate supervision, a supervisor must help students organise their work correctly, write academically and deal with feedback effectively to enhance learning. The supervisor's sustained support is needed to bridge the geographical isolation felt by distance learners.

Teaching entails explaining the subject matter and monitoring students' progress (Simpson, 2016). The supervisor can achieve this by providing comprehensive feedback, holding meetings, and using technology to communicate with students and enhance supervisor-student interactions. Assessment is both formal and informal, and it should be designed in a manner that helps students reflect on their strengths and weaknesses. Timely and comprehensive feedback scaffolds teaching and learning, fosters a connection between the supervisor and student, and eases the challenges and anxieties imposed by geographical separation (Uribe \& Vaughan, 2017). It teaches students to become self-regulated and increases their motivation, engagement, and achievement.

Emotional and organisational support is collectively referred to as non-academic support. Emotional support seeks to help students cope with the emotional side of learning and empower them to (a) develop a motivation for learning; (b) develop self-confidence; and (c) devise strategies to manage the stress of learning and assessment (Shikulo \& Lekhetho, 2020; Simpson, 2016). Pursuing a PhD through distance learning is a lonely and draining journey, which requires the supervisor to support students emotionally throughout their studies to ensure that they succeed. Motivation and self-confidence are essential for successful learning, and therefore, supervisors should foster these traits in students. Students who experience personal, emotional, and academic challenges should be afforded support and counselling. Organisational support entails helping students to (a) manage time effectively; (b) keep up with the pace of the course; and (c) create time for work, family, and other responsibilities (Simpson, 2016). Postgraduate students should balance these to fulfil their academic obligations and progress at the required speed.

Student support can be proactive or reactive (Simpson, 2016). It is proactive when initiated by the institution and reactive when the student seeks it. The supervisor and office of postgraduate studies are expected to reach out to students to provide necessary administrative, academic, and emotional support to enrich their learning experience and success. Similarly, students often direct their queries to the designated university personnel when they require support services to facilitate their learning.

\subsubsection{Student Collaboration in Distance Learning}

Other students in the same course can be another source of support by helping one another in 'self-help groups' or peer support (Simpson, 2016; Nsama \& Makoe, 2017). Such groups can promote students' engagement or meaningful involvement in the learning environment and a sense of connectedness or belief that one matters to others in the organisation. At Unisa, self-help groups are manifested by the increasing use of WhatsApp among students, who connect with their peers to obtain information about their studies (Madge et al., 2019). WhatsApp creates a social context for distance learners and empowers them to take charge of their learning because it is easily accessible, cheap, and enables them "to transfer, translate and transform their educational experience" (Madge et al., 2019, p. 272). Unisa has also created the myUnisa portal, an online communication tool between students and the university and among students. Indubitably, collaboration among students bolsters learning and allows them to learn with and from one another.

Simpson's notion of self-help groups ties in with Wenger's (2006) concept of communities of practice, which involve groups of people who engage in collective learning in a shared human endeavour. Communities of practice are "groups of people who share a concern, a set of problems, or a passion about a topic, and who deepen their knowledge and expertise in this area by interacting on an ongoing basis" (Wenger, McDermontt \& Snyder, 2002, p. 4). Since they are bound together by a shared vision and share knowledge and best practices, communities of practice tend to improve individual and organisational performance. In postgraduate studies, these could be students who collaborate to share scholarly views on their ongoing studies. Students' self-help groups could engender a sense of community, dispel feelings of isolation, and boost their motivation and persistence. 


\subsubsection{Institutional Student Support}

In distance education, students study at their own pace and in their own spaces. However, student support is provided to enhance learning and academic success. It mitigates the effects of a lack of lecturer-student interaction in a face-to-face situation. Unisa has steadily invested in significant technological infrastructure and human capacity development to scale up student support in all the critical areas of teaching and learning. It has transformed its mode of content delivery from print to a blend of print and online support (Mays \& Aluko, 2019).

Unisa uses communication tools such as blogs, Twitter, satellite broadcasting, Zoom, and Microsoft Teams to bridge the distance in distance education, stem student attrition, and enhance academic experience and completion rates (Unisa, 2021). It also encourages students to visit its regional centres to get advice, meet other students, use its counselling services, facilities, and library services to enrich learning, and connect with their peers through social media such as Facebook and WhatsApp.

While the SSS outlined above are open to all students, they are more helpful to undergraduates since postgraduate education requires independent study and individualised interaction between the student and supervisor. Therefore, the nature of interaction depends on the academic ingenuity and competence of the supervisor. The academic support rendered by the college is mainly in the form of research workshops for first-year students working on their proposals and research seminars for students at advanced stages of their studies. This leaves the bulk of student support entirely in the hands of supervisors.

\section{Method}

This study is anchored in the interpretivist paradigm, which assumes that humans interpret their world and act according to their interpretations (Kivunja \& Kuyini, 2017). Interpretivism uses a relativist ontology, which assumes that a phenomenon has various interpretations rather than a single truth that can be scientifically measured (Kivunja \& Kuyini, 2017). Consistent with this paradigm, the study followed a qualitative methodology to probe the Ethiopian doctoral students' views about the SSS provided by Unisa and understand this phenomenon deeply rather than generalise the findings to the whole population. Qualitative research answers questions of experience, perspective, and meaning from the participant's standpoint (Aspers \& Corte, 2019). A case study design was adopted to understand the situation from the participants' point of view, feelings, and lived experiences (Aspers \& Corte, 2019). Accordingly, a focus group interview was conducted with nine doctoral students to explore their perceptions of the SSS provided by Unisa to facilitate their learning, or what Simpson (2016) calls organisational support. The open-ended questions guided the discussion and enabled participants to express their opinions about this phenomenon using their own words.

The participants were conveniently selected, as only those who attended the workshop in Addis Ababa in December 2019 were interviewed. Convenience sampling allows the researcher to choose the samples that are convenient and accessible if they have the required characteristics of the target group (Denscombe, 2010). The focus group comprised nine male students: one in the first year, six in the second year, and one in the third and final years. Seven of these were lecturers at public universities, while two worked in other sectors. Ideally, focus groups should consist of six to nine participants to discuss a range of views (Denscombe, 2010). The discussion was conducted by two researchers, one interviewing and the other moderating the process. Before discussions commenced, the researchers advised the group members to give one another a chance to speak and not repeat the same issues.

\subsection{Data Analysis}

The responses from different participants were transcribed as captured in voice recordings. Data were analysed inductively, which involved reading through transcriptions several times to see patterns and themes that emerged from interviews, followed by identifying text segments related to the research questions (Liu, 2016). In inductive analysis, research findings emanate from frequent and dominant themes that emerge from raw data (Thomas, 2006). Afterwards, the text segments were coded and categorized using participants' expressions and the researcher's words (Denscombe, 2010). The categories were then reorganised to minimise overlaps. Finally, a model was developed after identifying the most important categories (Liu, 2016). Accordingly, thematic analysis was used, which included looking at the entire data set to identify recurring themes and summarise all the views collected. This enabled the researcher to organize, describe and report the themes that emerged from the data.

\subsection{Credibility and Confirmability}

Credibility or internal validity was guaranteed by giving the focus group interviews sufficient time (1 hour, 20 minutes), which enabled the researchers to familiarise themselves with the setting and establish rapport with the participants (Korstjens \& Moser, 2018). The findings are presented and interpreted as factually and accurately as possible to reflect the participants' original data, using direct quotes where necessary. To ensure confirmability, the 
entire process of data generation is described in detail. Data were captured on multiple electronic devices to minimise the chances of omissions or vagueness. The recordings were transcribed by a trained and experienced data transcriber who was not part of the research team to ensure accuracy and neutrality. The interpretation of the findings is not falsified or based on the researcher's viewpoint, but it is grounded in the data (Korstjens \& Moser, 2018). For reflexivity, the researchers clarified their role in the research process and set aside their preconceptions gained over the years of facilitating research workshops and supervising Ethiopian students to avoid contaminating the findings.

\subsection{Ethical Considerations}

As guided by the ethical clearance obtained from Unisa's Research Ethics Committee, before starting the interviews, the researchers explained the purpose of the research and the participants' right to abstain or withdraw from the study at any point without incurring any reprisals. Moreover, the participants were assured that the content of group discussions would only be known by those present (Denscombe, 2010). The researchers created a relaxed environment that made each participant feel valued. The discussion commenced only after obtaining informed consent from the participants and permission to record the interviews.

\section{Results}

The findings are presented thematically based on the prepared questions that probed the students' perceptions of the SSS they received from Unisa. For ease of reference, the participants are coded Interviewees 1 to 9. In some parts, the narratives deemed most pertinent are cited to bring forth the participants' voices, while in others, common themes are synthesised as discussed below. The findings are based on the emergent themes and sub-themes depicted in Table 2.

Table 2. Emergent themes and sub-themes

\begin{tabular}{ll}
\hline Theme & Sub-themes \\
\hline Postgraduate Students' views about their studies & Contentment with studies \\
& Contentment with research workshops \\
& Career prospects \\
& Desire for more knowledge \\
& Institutional recognition and prestige \\
& Effect of strong supervisor's support \\
& Effective communication with supervisor \\
Administrative support & Supervisor competency \\
& ICT support \\
& Personal challenges \\
Academic support & Library support \\
& Annual student workshops \\
Student research workshops & Supervisor support \\
Topics covered in workshops & Feedback turnaround time \\
Workshop organisation \\
Workshop facilities \\
Internet connection \\
Views about content and facilitation \\
Financial support \\
Workshop facilities \\
Workshop duration \\
Financial support \\
Library support \\
\hline
\end{tabular}




\subsection{Postgraduate Students' Views about Their Studies}

Participants were first asked to share their views about studying for a $\mathrm{PhD}$, and they all expressed satisfaction with this. This is because doctoral studies represent a significant milestone in students' lives and fulfil their dreams, as expressed in the responses below.

I am very proud to be pursuing my doctoral studies with this University. I have been eager to do a PhD in my career, and eventually, I enrolled for it, specialising in education management. I am happy to attend this workshop, and I hope I will graduate successfully and impart the knowledge I have acquired to others (Interviewee 1).

On the same issue, two participants responded as follows:

I am proud to be a PhD student. I have had a fruitful experience over the last three years. I believe this programme will develop me in my professional career and sharpen my research and academic skills (Interviewee 2).

I am pleased to do a PhD with Unisa because this is a good opportunity to access education. It has allowed me to do research supervised by experienced foreign lecturers, and I believe by the time I complete my studies, I will be a well-grounded researcher (Interview 3).

Two second-year students responded this way:

I am very proud to do my PhD with this University because it is internationally recognised. This gives me a chance to interact with other international students and benefit from foreign experts. The engagements we have are inspiring and enriching (Interviewee 4).

I am very grateful to do my PhD with Unisa because it has many researchers. Even strong commitment I show in my work, I have learned from them. They are very supportive, and the way they talk makes every lesson great. So, I am determined to keep going until I complete (Interviewee 5).

What emerges from the above excerpts is that participants were keen to embark on their doctoral studies, arguably because most of them were lecturers at different universities where career advancement is linked to the attainment of doctoral degrees and research output. They cherished the international exposure and were optimistic that they would be equipped with advanced research skills. Some reported that the commitment shown by their supervisors and facilitators inspired them to be diligent in their studies and work.

\subsection{Administrative Support}

Regarding the administrative support that they received from the University in aspects such as correspondence, resolving challenges, and supervisor allocation, the participants reported:

I am okay with the allocated supervisor because I communicate with him well. When I present my problem, he responds within a week. Therefore, it is good (Interviewee 6).

Interviewee 7 stated:

You know, I only communicate with my supervisor. He supports me in every way. He has been helping me in my studies throughout the journey. Therefore, I am pleased with the support I receive.

When asked about any serious challenges they had experienced, one participant responded:

Regarding content and research methodologies, I am happy. Last year, I was disconnected from my supervisor for five months. Through the ICT support of the regional centre, the problem was solved, and I was able to communicate with my supervisor again, and there is no problem now. It was only those technological challenges I encountered (Interviewee 9).

Following further probing about serious challenges, one participant stated:

I do not have any challenges with my supervisor. He guides me, supports me, and responds to my queries very promptly. I have my challenge because I have a family, and I reside in a rented house. I am a contract worker, I do not have enough time to work on my studies, and I do not have any communication and internet facilities at home. So, these are only my challenges. Otherwise, from the side of the University, I do not face any challenges. They are supportive (Interviewee 2).

On being probed about their study challenges, some participants revealed: 
When going through the library at my regional centre, I did not come across recent publications in my field. As a mega university, you can buy new books, update the book loan system, improve the online library, and make it more user-friendly (Interviewee 4).

I have enjoyed joining this institution, and I have acquired tremendous skills as a writer on parenting. I made the right decision by joining the Department of Educational Psychology, and I have benefited greatly. However, I have a challenge with competing priorities of writing a new book and focusing on my studies (Interviewee 5).

The above extracts indicate that the interviewees were generally satisfied with the University's administrative support. Their satisfaction mainly stemmed from good working relationships and effective communication with their supervisors, whom they described as efficient in responding to their queries, guiding their studies, and giving them comprehensive feedback. However, three participants reported encountering personal problems, namely a lack of communication facilities, unreliable internet, insufficient income, and competing priorities, which hampered their studies.

Some participants expressed frustration about a lack of recent publications at the regional centre and a short book loan period and requested that this situation be improved. Another student was anxious about the money paid to accredited language editors, which typically happens when final-year students submit their theses for examination. However, there are anecdotal reports that some supervisors demand that postgraduate students with serious English language problems engage editors throughout the writing of their dissertations. This underscores the need for the University to provide language support for such students to ensure that they learn and avoid outsourcing the writing to third parties. As Simpson (2016) argued, institutions should provide organisational support to optimise students' learning and success. Institutional support seeks to identify and assist students at risk of failure and dropout to master the required material and succeed in their studies through proactive measures that sustain their motivation and engagement (Carr \& London, 2019; Sánchez-Elvira Paniagua \& Ormond Simpson, 2018).

\subsection{Academic Support}

Concerning their experiences of academic support in aspects such as supervisor availability, supervisor-student interactions, and feedback, the participants responded as follows:

One is what you have been doing annually by conducting workshops for us and organising seminars. This helps to fill our gaps and refresh our knowledge. Moreover, my supervisor is efficient; when she receives my work, she responds on time. So, there is no problem (Interviewee 6).

The interviewer further asked about the participants' interactions with their supervisors, and Interviewee 6 responded as follows:

Supervision depends on individual supervisors. Some supervisors are considerate, friendly, and supportive. However, in some cases, I do have problems.

When asked to specify the turnaround time that supervisors took to give them feedback in terms of weeks, Interviewee 6 stated enthusiastically:

Not weeks, within days, he gives me feedback with every paragraph and step marked, and then I work on his comments.

The above narratives indicate that the participants identified academic support provided by the College of Education as positive and framed it in terms of the annual research workshops facilitated. They said these addressed their questions on research methodologies and postgraduate procedures. They reported that these workshops allowed them to interact with the facilitators, who were keen to assist them on their challenges and communicate these to their supervisors when they returned to the main campus.

The participants were generally satisfied with their supervisors' academic support, and some spoke admiringly about their efficiency shown by quick turnaround times, comprehensive feedback, and readiness to assist them academically. Interviewee 6 revealed that he had a good working relationship with his supervisor, whom he described as supportive and efficient. However, he clarified that the relationship between students and supervisors differed from one individual to another and that some supervisors were friendly and helpful while others were not.

\subsection{Student Research Workshops}

Participants who had been in the doctoral programme for some time were asked to share their views on the organisation of the workshops and content covered. They were generally satisfied with these, as expressed in the extract below. 
For me, the organisation of today's workshop and the previous ones was good. The lecturers are well prepared and deliver their presentations well. However, there are a few limitations like poor internet connection and facilities. Otherwise, the workshop is well organised (Interviewee 9).

Regarding the workshops, the overall theme that emerged is that they were well organised and well facilitated. However, they decried the poor condition of workshop venues and unstable Wi-Fi, which affected their motivation levels.

\subsection{Topics Covered in the Workshops}

Concerning the topics covered and how they experienced the workshops, the participants responded as follows:

The topics covered in the workshops are interesting, but we need some presentation slides for further reading (Interviewee 1 ).

When directed to focus on the content and facilitation of presentations, one participant harked back to the problem of logistics:

The content and facilitation used by facilitators are interesting, but concerning workshop facilities, that part is not good (Interviewee 2).

When asked about the workshop duration, one interviewee commented:

A week is enough but holding the workshop at the end of the year is awkward. It would be ideal to have another workshop in the middle of the year (Interviewee 3).

Overall, the participants were satisfied with the topics presented on administrative support and research methodologies and the interactive approach that stimulated discussion. They agreed that a five-day duration was enough. However, they suggested that the workshops be held twice a year rather than once at the end of the academic year when they were finalising their proposals.

\subsection{Additional Support Needed by Students}

Finally, participants were invited to suggest additional support that they needed to succeed in their studies, and one responded as follows:

Financial support. It is not for leisure. I went to four universities and wasted so much money. So, if you are thinking about leisure, that is wrong. From my experience, fees take away a lot of money, including transfer costs (Interviewee 4).

Interviewee 5 emphasised the financial burden of studying and the need for financial support for self-sponsored students as follows:

To come to Addis, most of us drive for 500 to 600 kilometres. The library lends us books for only 20 days, which is short and challenging for us. The days should be extended (Interviewee 5).

Five of the nine participants reported being self-sponsored and requested financial support as they could barely afford to pay their fees and other educational costs due to financial constraints. Interviewee 6 revealed that paying high fees "makes it difficult to complete the degree within five years" and pleaded for financial assistance from the University. Those sponsored by the government said the bursary was inadequate, as it covered only tuition fees and data collection as opposed to the University's full bursary, which covered all items. Finally, students from far-flung areas were frustrated by the distance they travelled to the workshop venues and the regional library's short book loan period.

\section{Discussion}

Effective student support plays a pivotal role in ODL institutions, as it mitigates the effects of the distance education deficit and enhances student success. This is particularly significant in developing countries that lack robust ICT infrastructure. In this study, all the Ethiopian doctoral students expressed satisfaction at studying with Unisa and viewed this as an opportunity to acquire an education. This is because most of them were university lecturers where doctoral qualifications are valued for career advancement. Some reported being inspired by the commitment shown by their supervisors and workshop facilitators. Similar earlier studies have established that when their academic engagement, self-esteem, and sense of competence are boosted, distance learners become more effective as they vigorously and persistently pursue learning (Workman \& Stenard, 1996; van Rooij et al., 2019).

Regarding administrative support, the participants reported being satisfied with the services they received from the University. Administrative support includes assisting students in registration, funding, guidance, advisory services, and forging a healthy distance learning environment (Nsama \& Makoe, 2017). Technology plays a crucial role in 
administrative support, and therefore, all staff members should use it effectively to optimise students' learning experience, particularly in the current COVID-19 crisis where most institutions operate virtually. Although participants were asked about administrative support, their responses veered towards supervisor support, understandably because postgraduate students interact more with their supervisors than administrative staff. They appreciated their supervisors' promptness in addressing their queries and giving them comprehensive feedback that challenged them to think critically and work harder. In similar studies, high-quality supervision characterised by the supervisors' supportive and collegial relationships with students and encouragement has been identified as the most influential factor that affects doctoral students' learning experience and increases their satisfaction (Sverdlik, Hall, McAlpine \& Hubbard, 2018; van Rooij et al., 2019). Additional factors include commitment, adhering to timelines, openness to different research approaches, and cordial supervisor-supervisee relationships.

It has also been established that postgraduate students prefer experienced supervisors who challenge them intellectually, explain the subject clearly, guide their learning, and critique their work skilfully to get the best out of them (Baydarova et al., 2021). Therefore, the supervisor and supervisee should develop a healthy relationship and manage the supervisory process through regular interactions geared towards helping the candidate contribute new scientific knowledge (Sidhu, Kaur, Fook \& Yunus, 2014). This requires supervisor availability, holding regular meetings and open discussions with $\mathrm{PhD}$ students about roles, and providing timely responses to questions and feedback on students' written work (Sverdlik et al., 2018).

In general, the participants appreciated the academic support they received from the University in the form of annual research workshops, which enabled them to meet their supervisors and staff from the main campus to discuss academic and administrative issues. From the US context, Workman and Stenard (1996) noted that distance learners valued the chance to interact with on-campus faculty to learn more about policies and procedures for their studies. Academic support entails assisting students to acquire academic skills such as research techniques, academic writing, and managing their studies (Martirosyan et al., 2019). It leads to timely completion and increases students' motivation and satisfaction.

This research has established that the students' satisfaction and motivation mainly stemmed from the strong academic support of their supervisors who readily assisted them. This corroborates Heeralal's (2015) finding that most postgraduate students in the College of Education at Unisa were satisfied that their supervisors met their expectations. He established that students expected their supervisors to guide them, respond promptly to emails and maintain good relationships with them. Similarly, Sidhu et al.'s (2014) study in Malaysia and the UK found that postgraduate students preferred supervisors who were not only committed and competent but also friendly and supportive as this created a smooth supervisory relationship. This motivates students to persist and overcome the challenges of situation and time, deal with stress and become independent learners (Simpson, 2013). Baydarova et al. (2021) described this as a student-centred supervision approach that gives students a greater say on what and how they learn, given their unique backgrounds, needs, and capabilities. The supervisor can grant students more autonomy by giving them space to make choices about their studies and respecting their views, which increases their motivation and self-efficacy (van Rooij et al., 2019).

Concerning research workshops, all the participants stated that they were well organised and helpful. They nonetheless registered their displeasure with the poor condition of facilities and unstable internet. Reliable internet connectivity is essential in distance education, as it facilitates and supports learning, and therefore, institutions should encourage students to participate in online learning (Van den Berg, 2020). Lecturers can make online learning interactive by using technology and videoconferencing, particularly during the ongoing COVID-19 pandemic (Dhawan, 2020). Therefore, ODL students must always be digitally connected to the institution to improve the quality of learning and maintain two-way communication. In turn, the institution should provide ubiquitous, personalised and adaptive support to students to meet their unique learning needs (Sánchez-Elvira Paniagua \& Ormond Simpson, 2018). As Van den Berg (2020) proposed, instructors should gather information about their students' different contexts to cater for these differences in their courses and support. Finally, Usher and McCormack's (2021) study in Australia concluded that doctoral students' participation in workshops and conferences and networking with others on research and other matters is critical for their learning and success. Simpson (2016) characterised teaching, postgraduate supervision, and workshop facilitation as cognitive support, which helps students develop skills needed for effective learning, and deal with assessment.

Participants were generally happy about postgraduate procedures, and research methodologies covered in the workshops and appreciated the interactive facilitation methods used. Regarding any additional support they needed to succeed in their studies, all the self-sponsored participants said they desperately needed financial support, while those 
sponsored by the government reported that the bursary was inadequate. Similarly, Martirosyan et al.'s (2019) study in the US found that international students identified financial support through scholarships and campus jobs as highly important. Scholarships enhance students' satisfaction, persistence, progression, and timely graduation because they influence academic integration and raise their academic expectations and commitment (Martirosyan et al., 2019; Sverdlik et al., 2018).

\section{Recommendations}

In general, participants expressed satisfaction with their supervisors. However, a few were reported to be taking too long to review students' written work and inefficient. To alleviate this, it is recommended that supervisors be trained on effective supervision of postgraduate students from diverse cultural and economic backgrounds. Students should also be assisted to form self-help groups to support one another academically and emotionally. Literature indicated that the English language barrier hinders the progress and success of many students who do not speak English as a native language (Martirosyan et al., 2019). Van Rensburg, Mayers and Roets (2016) proposed that such students should be offered writing support to improve their command of English so that they can write effectively at an appropriate level. As Martirosyan et al. (2019) noted, top universities in the US offer language and writing support to international students to improve their academic success. Therefore, HEIs should provide language support for postgraduate students with English language deficiencies to improve their writing competency. Lastly, countries and sponsors should be requested to sponsor unfunded students to ease their financial pressure, which would raise their motivation, persistence, and success.

\section{Conclusion}

Contrary to expectations, most Ethiopian postgraduate students in this study were satisfied with the administrative, academic, and technical support they received from Unisa, particularly with their supervisors' commitment and efficiency. However, some subtly expressed dissatisfaction with specific units, notably the regional library for lacking enough books, granting a short book loan period, a lack of financial support, and unsupportive supervisors. They generally valued academic guidance and support provided by their supervisors more than other forms of institutional support and viewed them as vital leaders who should effectively guide their learning to completion. They admired supportive supervisors who displayed deep content knowledge and competence in reviewing their work, giving them timely feedback, and addressing their queries. Finally, most students viewed research workshops and seminars as critical platforms that reinforced their learning and enabled them to interact with the facilitators and their peers.

\section{Acknowledgements}

This research was funded by the Research Directorate of the University of South Africa under the Open Distance Learning Research Support Programme (ODL-RSP). Special thanks to the participants, the Unisa-Ethiopia Centre staff, and the project team members, Professors: Mishack Gumbo, Velisiwe Gasa, Meahabo Magano, and Joseph Dhlamini.

\section{References}

Aspers, P., \& Corte, U. (2019). What is qualitative in qualitative research. Qualitative Sociology, 42, 139-160. https://doi.org/10.1007/s11133-019-9413-7

Baydarova, I., Collins, H. E., \& Ait Saadi, I. (2021). Alignment of doctoral student and supervisor expectations in Malaysia. International Journal of Doctoral Studies, 16, 1-29. https://doi.org/10.28945/4682

Budiman, R. (2018). Factors related to students' drop out of a distance language learning programme. Journal of Curriculum and Teaching, 7(2), 12-19. https://doi.org/10.5430/jct.v7n2p12

Carr, B. B., \& London, R. A. (2019). The role of learning support services in university students' educational outcomes. Journal of College Student Retention: Research, Theory and Practice, 21(1), 78-104. https://doi.org/10.1177/1521025117690159

Chaney, B., Muraskin, L. D., Cahalan, M. W., \& Goodwin, D. (1998). Helping the progress of disadvantaged students in higher education: The federal student support services program. Educational Evaluation and Policy Analysis, 20(3), 197-215. https://doi.org/10.3102/01623737020003197

Denscombe, M. (2010). The good research guide: For small-scale social research projects (4th edition). Berkshire: Open University Press.

Dhawan, S. (2020). Online Learning: A panacea in the time of COVID-19 crisis. Journal of Educational Technology Systems, 49(1), 5-22. https://doi.org/10.1177/0047239520934018 
Fetene, G. T., \& Tamrat, W. (2021). The PhD journey at Addis Ababa University: Study delays, causes and coping mechanisms. International Journal of Doctoral Studies, 16, 319-337. https://doi.org/10.28945/4744

Gasa, V., \& Gumbo, M. (2021). Supervisory support for Ethiopian doctoral students enrolled in an open and distance learning institution. International Journal of Doctoral Studies, 16, 47-69. https://doi.org/10.28945/4676

Heeralal, P. J. H. (2015). Improving postgraduate supervision in an open and distance learning environment: A case study at the College of Education, University of South Africa. South African Journal of Higher Education, 29(3), 87-100. https://doi.org/10.20853/29-3-490

Jancey, J., \& Burns, S. (2013). Institutional factors and the postgraduate student experience. Quality Assurance in Education, 21(3), 311-322. https://doi.org/10.1108/QAE-Nov-2011-0069

Kivunja, C., \& Kuyini, A. B. (2017). Understanding and applying research paradigms in educational contexts. International Journal of Higher Education, 6(5), 26-41. https://doi.org/10.5430/ijhe.v6n5p26

Korstjens, I., \& Moser, A. (2018). Series: Practical guidance to qualitative research. Part 4: Trustworthiness and $\begin{array}{llll}\text { publishing. European Journal of } & \text { General }\end{array}$ https://doi.org/10.1080/13814788.2017.1375092

Lekhetho, M. (2021). Exploring factors influencing the performance of high-achieving secondary schools in Lesotho. Issues in Educational Research, 31(3), 871-890. http://www.iier.org.au/iier31/lekhetho.pdf

Liu, L. (2016). Using generic inductive approach in qualitative educational research: A case study analysis. Journal of Education and Learning, 5(2), 129-135. https://doi.org/10.5539/jel.v5n2p129

Madge, C., Breines, M. R., Dalu, M. T. B., Gunter, A., Mittelmeier, J., Prinsloo, P., \& Raghuram, P. (2019). WhatsApp use among African international distance education (IDE) students: Transferring, translating and transforming educational experiences. Learning, Media and Technology, 44(3), 267-282. https://doi.org/10.1080/17439884.2019.1628048

Manyike, T. V. (2017). Postgraduate supervision at an open distance e-learning institution in South Africa. South African Journal of Education, 37(2), 1-11. https://doi.org/10.15700/saje.v37n2a1354

Martirosyan, N. M., Bustamante, R. M., \& Saxon, D. P. (2019). Academic and social support services for international students: Current practices. Journal of International Students, 9(1), 172-191. https://doi.org/10.32674/jis.v9i1.275

Mays, T. (2000). Learner support: A South African programme perspective. Retrieved from https://www.saide.org.za/resources/Conf\%202000/4.\%20Mays\%20Key\%20note\%20Learner\%20Support.pdf

Mays, T., \& Aluko, F. R. (2019). Agile administrative choreographies for multimode education at the University of Pretoria. Distance Education, 40(1), 5-19. https://doi.org/10.1080/01587919.2018.1553563

Ngema, M., \& Lekhetho, M. (2019). Principals' role in managing teacher professional development through a training needs analysis. Problems of Education in the 21st Century, 77(6), 758-773. https://doi.org/10.33225/pec/19.77.758

Nsama, A., \& Makoe, M. (2017). Evaluating quality of students' support services in open distance learning. Turkish Online Journal of Distance Education, 18(4), 91-103. https://doi.org/10.17718/tojde.340391

Prinsloo, P. (2019). South Africa. In O. Zawacki-Richter, \& A. Qayyum, (Eds.), Open and Distance Education in Asia, Africa and the Middle East: National Perspectives in a Digital Age (pp. 67-82). Singapore: Springer Open. https://doi.org/10.1007/978-981-13-5787-9

Sánchez-Elvira Paniagua, A., \& Simpson, O. (2018). Developing student support for open and distance learning: The EMPOWER Project. Journal of Interactive Media in Education, 1(9), 1-10. https://doi.org/10.5334/jime.470

Shikulo, L., \& Lekhetho, M. (2020). Exploring student support services of a distance learning centre at a Namibian university. Cogent Social Sciences, 6(1), 1737401. https://doi.org/10.1080/23311886.2020.1737401

Sidhu, G. K., Kaur, S., Fook, C. Y., \& Yunus, F. W. (2014). Postgraduate supervision: Comparing student perspectives from Malaysia and the United Kingdom. Procedia - Social and Behavioral Sciences, 123(2014), 151-159. https://doi.org/10.1016/j.sbspro.2014.01.1409

Simpson, O. (2013). Student retention in distance education: Are we failing our students? Open Learning: The Journal of Open, Distance and e-Learning, 28(2), 105-119. https://doi.org/10.1080/02680513.2013.847363 
Simpson, O. (2016). Student support services for success in open and distance learning. Retrieved from https://www.researchgate.net/publication/294428578_'Student_Support_Servicesfor_Success_in_Open_and_Di stance_Learning'/download

Steyn, M. G., Harris, T., \& Hartell, C. G. (2014). Institutional factors that affect black South African students' perceptions of early childhood teacher education. South African Journal of Education,34(3), 1-7. https://doi.org/10.15700/201409161038

Sverdlik, A., Hall, N. C., McAlpine, L., \& Hubbard, K. (2018). Journeys of a PhD student and unaccompanied minors. International Journal of Doctoral Studies, 13, 361-388. https://doi.org/10.28945/4113

Tait, A. (2003). On institutional models and concepts of student support services: The case of the Open University UK. International Review of Research in Open and Distance Learning, 4(1), 1-11. https://doi.org/10.19173/irrodl.v4i1.134

Thomas, D. R. (2006). A general inductive approach for analyzing qualitative evaluation data. American Journal of Evaluation, 27(2), 237-246. https://doi.org/10.1177/1098214005283748

Tinto, V. (2017). Through the eyes of students. Journal of College Student Retention: Research, Theory and Practice, 19(3), 254-269. https://doi.org/10.1177/1521025115621917

Torka, M. (2020). Change and continuity in Australian doctoral education: $\mathrm{PhD}$ completion rates and times (2005-2018). Australian Universities Review, 62(2), 69-82. https://files.eric.ed.gov/fulltext/EJ1267338.pdf

Unisa-Ethiopia Centre. (2021). College of Education Graduates: 2011-2020. Unpublished documents.

University of South Africa. (2021). Student records for 2021. Unpublished documents.

University of South Africa. (2021). Open distance e-learning (ODeL) is a different way of learning. Retrieved from https://www.unisa.ac.za/sites/corporate/default/Apply-for-admission/Honours-degrees-\&-postgraduate-diploma s/ODL,-Unisa-and-postgraduate-studies/Open-Distance-Learning-(ODL)-is-a-different-way-of-learning

Uribe, S. N., \& Vaughan, M. (2017). Facilitating student learning in distance education: A case study on the development and implementation of a multifaceted feedback system. Distance Education, 38(3), 288-301. http://doi.org/10.1080/01587919.2017.1369005

Usher, W., \& McCormack, B. A. (2021). Doctoral capital and well-being amongst Australian PhD students: Exploring capital and habitus of doctoral students. Health Education, 121(3), 322-336 https://doi.org/10.1108/HE-11-2020-0112

Van den Berg, G. (2020). Context matters: Student experiences of interaction in open distance learning. Turkish Online Journal of Distance Education, 21(4), 223-236. https://doi.org/10.17718/tojde.803411

Van Rensburg, G. H., Mayers, P., \& Roets, L. (2016). Supervision of postgraduate students in higher education. Trends in Nursing, 3(1). https://doi.org/10.14804/3-1-55

van Rooij, E., Fokkens-Bruinsma, M., \& Jansen, E. (2019): Factors that influence PhD candidates' success: the importance of $\mathrm{PhD}$ project characteristics. Studies in Continuing Education, 43(1), 48-67. https://doi.org/10.1080/0158037X.2019.1652158

Wenger, E. (2006). Communities of practice: A brief introduction. Retrieved from https://www.ohr.wisc.edu/cop/articles/communities_practice_intro_wenger.pdf

Wenger, E., McDermontt, R., \& Snyder, W. M. (2002). Cultivating communities of practice: A guide to managing knowledge. Boston, MA: Harvard Business School Press.

Woodley, A., \& Simpson, O. (2014). Student dropout: The elephant in the room. In O. Zawacki-Richter, \& T. Anderson, (Eds), Online distance education: Towards a research agenda (pp. 459-484). Athabasca: Athabasca University Press.

Workman, J. J., \& Stenard, R. A. (1996). Student support services for distance learners. DEOSNEWS, 6(3), 1-11. https://learningdesign.psu.edu/assets/uploads/deos/deosnews6_3.pdf

\section{Copyrights}

Copyright for this article is retained by the author(s), with first publication rights granted to the journal.

This is an open-access article distributed under the terms and conditions of the Creative Commons Attribution license (http://creativecommons.org/licenses/by/4.0/). 